\title{
MONITORING OF WEED INFESTATION OF CROPS AT MODERN RESOURCE-SAVING WAYS OF THE MAIN SOIL PROCESSING
}

\author{
МОНИТОРИНГ ЗАСОРЕННОСТИ ПОСЕВОВ ПРИ СОВРЕМЕННЫХ \\ РЕСУРСОСБЕРЕГАЮЩИХ СПОСОБАХ ОСНОВНОЙ ОБРАБОТКИ ПОЧВЫ
}

A. Zabrodkin, A. Novikova, Post-Graduate Students

А.А. Забродкин, А.С. Новикова, аспиранты

S. Plygun, Candidate of Agricultural Sciences

С.А. Плыгун, кандидат сельскохозяйственных наук

V. Lobkov, Doctor of Agricultural Sciences

B.T. Лобков, доктор сельскохозяйственных наук

Orel State Agrarian University, Orel City, Russia

Орловский государственный аграрный университет, г. Орёл, Россия

Phone: +7 (4862) 45-40-37, E-mail: borpli@ rambler.ru

Received September 3, 2012

\begin{abstract}
The results of investigation of influence of different soil processing methods on weed infestation of crops and their influence on agricultural crop efficiency in the conditions of the Orel region are examined. The analysis and estimation of agricultural crop infestation including different quantitative characters: rating system, weed plant phytomass, projective cover in comparison with projective cover of cultivated plants, specific number of weed plants and their influence on agricultural crop efficiency are carried out. The influence of different seeds variants and modern basic soil cultivation on weed infestation of crops, utilization of foreign seeding complex John Deere 730 and national seeding machine SZ-5,4 is shown.
\end{abstract}

\section{АННОТАЦИЯ}

Рассмотрены результаты исследований влияния различных способов обработки почвы на засоренность посевов и их влияние на продуктивность сельскохозяйственных культур в условиях Орловской области. Проведен анализ и оценка засоренности сельскохозяйственньх культур, включающий в себя различные количественные признаки: бальная оценка, фитомасса сорных растений, проективное покрытие по сравнению с проективным покрытием культурных растений, видовое количество сорньх растений и их влияние на продуктивность сельскохозяйственных культур. Показано влияние различных вариантов посева и современной основной обработки почвы на засоренность посевов, применения импортного посевного комплекса John Deere 730 и отечественной сеялки С3-5,4.

\section{KEY WORDS}

Biomass; Plant production; Weeding; Pollutants; Soil fertility; Crops; Species; Forecasting; Soil.

\section{КЛЮЧЕВЫЕ СЛОВА}

Биомасса; Продуктивность; Обработка почвы; Уровень засоренности; Фитомасса; Агроценоз; Агротехника; Почва.

Интенсификация растениеводства является альтернативой экстенсивному направлению его развития. В последнее время нега- тивные последствия мощного антропогенного процесса на почву очевидны и необходимо учитывать экологические последствия агро- 
технологий. В практике растениеводства проводят мониторинговые исследования засоренности посевов для получения информации об уменьшении продуктивности сельскохозяйственных культур из-за сорных растений. В настоящее время существует целый ряд методических подходов к этому вопросу, но среди них нет универсального [11].

Активное внедрение интенсивного земледелия во второй половине XX века привлекло внимание к вопросу учета и регулирования роста и развития сорного компонента в агроценозе, что положительно влияет на урожайность возделываемых культур [5]. Современные меры защиты посевов от сорняков разнообразны (агротехника, сорт, подготовка семенного материала), но их применение без информации по мониторингу засоренности малоэффективно.

Стационарные исследования позволяют оценить уровень засоренности поля и агротехники. В исследованиях применялась количественно-весовой и видовой методы учета. При этом проводилось несколько учетов засоренности опытных участков: в середине и конце вегетационного периода исследуемых растений $[4,10,12]$.

В наших опытах изучались следующие варианты обработки почвы (фактор А):

1. Вспашка оборотным плугом LEMKEN;

2. Вспашка ПЛН-3-35;

3. Обработка почвы KOS-ом;

4. Плоскорезная обработка;

5. Нулевая обработка.

В опыте сравнивались 2 посевных комплекса (фактор В):
1. Отечественная сеялка С $3-5,4$;

2. Импортный посевной комплекс John Deere 730.

Нормы минеральных удобрений по всем вариантам обработки почвы были одинаковыми - 400кг/га фоном. Вносилась тукосмесь, азотно-фосфорно-калийное гранулированное удобрение (NPK 18:18:18).

Все варианты опыта заложены в трехкратной повторности. Площадь делянки 0,36га, общая площадь опыта 6га. Возделывались викоовсяная смесь - вика - Алла, овес Привет в соотношении 1:2, озимая пшеница Московская 39, просо - Квартет.

Агроклиматические условия в 2011-2012 годах были благоприятными для возделывания сельскохозяйственных культур по сравнению с засушливым вегетационным периодом 2010 года. Почва опытного поля имеет следующие агрохимические показатели: содержание элементов питания: гумуса 2,694,46\%; подвижного фосфора - 8,1 мг\100 гр почвы; подвижного калия - 5,8 мг\100 гр почвы.

Для характеристики уровня засоренности обследуемых посевов при глазомерном учете применялись шкалы Мальцева [8], Друде [14], Туликова [13]. Учет сорного компонента проводился визуально. Глазомерные методы основаны на абсолютной численности сорняков на единицу площади (Таблица 1).

В качестве показателя, характеризующего разные уровни засоренности, используется фитомасса сорняков (Таблица 2).

Таблица 1 - Бальная градация оценки обилия сорных растений

\begin{tabular}{|c|c|c|c|c|c|}
\hline \multirow{2}{*}{ Уровень обилия, балл } & \multicolumn{5}{|c|}{ Вариант обработки почвы и посевного агрегата } \\
\hline & ПЛН-3-35 & LEMKEN & KOS & Плоскорез & Нулевая \\
\hline Друде & 3 & 3 & 3 & 3 & 4 \\
\hline Мальцев & 2 & 2 & 2 & 2 & 3 \\
\hline Туликов & 2 & 2 & 2 & 2 & 3 \\
\hline
\end{tabular}

Таблица 2 - Масса сорняков по фазам вегетации культур, среднее за 3 года исследований, г/м²

\begin{tabular}{|c|c|c|c|c|c|}
\hline \multirow{2}{*}{$\begin{array}{c}\text { Вид обработки } \\
\text { почвы }\end{array}$} & \multirow{2}{*}{ Высевающий агрегат } & \multicolumn{2}{|c|}{ Выход в трубку } & \multicolumn{2}{|c|}{ Полного созревания } \\
\hline & & Сырая масса, гр & Сухая масса, гр & Сырая масса, гр & Сухая масса, гр \\
\hline \multirow{2}{*}{ LEMKEN } & C $3-5,4$ & 15,61 & 6,76 & 83,34 & 41,67 \\
\hline & John Deere 730 & 27,81 & 10,04 & 30,12 & 9,8 \\
\hline \multirow{2}{*}{ ПЛН- 3-35 } & C $3-5,4$ & 18,36 & 3,56 & 70,51 & 23,67 \\
\hline & John Deere 730 & 51,19 & 20,04 & 46,29 & 22,67 \\
\hline \multirow{2}{*}{ KOS } & C $3-5,4$ & 27,83 & 19,44 & 96,67 & 40,21 \\
\hline & John Deere 730 & 18,49 & 8,72 & 66,78 & 33,34 \\
\hline Плоскорез & $\mathrm{C} 3-5,4$ & 32,48 & 12,64 & 61,89 & 21,61 \\
\hline
\end{tabular}




\begin{tabular}{|c|c|c|c|c|c|}
\hline & John Deere 730 & 54,32 & 23,24 & 60,05 & 25,12 \\
\hline \multirow{2}{*}{ Нулевая обработка } & C $3-5,4$ & 132,02 & 47,75 & 158,72 & 45,5 \\
\hline & John Deere 730 & 148,17 & 53,75 & 125,57 & 39,2 \\
\hline
\end{tabular}

При анализе сырой массы сорняков в фазу выхода в трубку в среднем за Згода исследований можно сделать вывод, что наибольшая сырая масса наблюдается при посеве John Deere 730 по всем вариантам обработки почвы, кроме обработки почвы КОСом. Абсолютно сухая масса сорняков также наблюдается при посеве John Deere 730 по всем вариантам обработки почвы, кроме обработки почвы КОСом.

В фазу полного созревания отмечается обратная тенденция. Наибольшая сырая масса при посеве С3-5,4 по всем вариантам обработки почвы. Абсолютно сухая масса сорняков также больше при посеве С3-5,4 по всем вариантам обработки почвы, кроме обработки почвы плоскорезом. Это объясняется тем, что на вариантах обработки почвы при посеве С35,4 в фазу полного созревания происходит увеличение численности многолетних сорняков. Сорные растения взаимодействуют с культурными растениями на популяционном уровне. В основе взаимодействия лежит конкуренция за ресурсы среды (питательные вещества, воду, свет), аллелопатия, паразитизм [12,1-3].

Для получения представления о взаимодействии растений в посеве сравнивали проективное покрытие сорняков относительно культурного растения. При геоботаническом обследовании использована 4-бальная шкала[9]. По ней влияние основной современной обработки почвы опытного поля можно характеризовать в 2 балла, т.е. сорные растения встречаются довольно часто, однако их проективное покрытие значительно меньше, чем культурного растения.
По степени потребности в увлажнении сорные растения делятся на: ксеромезофиты (до 9\%) - вьюнок; гигромезофиты (до 14\%) влаголюбивые (хвощ), большинство сорных растений относятся к мезофитам (до77\%). Кроме влаги сорные растения активно поглощают питательные вещества: азот - осот, щирица, хвощ, марь белая, бодяк (137-280 кг $\mathrm{N} /$ га); фосфор - хвощ, марь белая (40-92 кг $\mathrm{P} /$ га); калий - хвощ, щирица, горец шероховатый, осот полевой (235-286 кгК/га). Сорняки, активно усваивая питательные вещества, обладают меньшей биологической продуктивностью в сравнении с культурными растениями. Большая часть питательных веществ аккумулируется в семена сорняков, корневой системе и по этой причине долгое время не возвращается в почву.

Основной показатель, характеризующий вредоносность сорняков в посевах сельскохозяйственных культур - это уровень урожайности (таблица 3) в связи с конкуренцией сорных растений за условия жизни при совместном произрастании с культурными растениями в агроценозе [3]. Под конкуренцией в данном случае понимается недоиспользование культурными растениями факторов внешней среды. Систематический недобор от вредоносности сорных растений потенциального урожая по стране сельскохозяйственных культур составляет $24-47 \%$ или 71млн.т. зерновых единиц.

Величина потерь урожая так же зависит и от продолжительности совместного произрастания сорняков в посеве культуры [2].

Таблица 3 - Продуктивность культур севооборота, ц/га*

\begin{tabular}{|c|c|c|c|}
\hline \multirow{2}{*}{ Вариант опыта } & \multicolumn{3}{|c|}{ Продуктивноость, ц|га } \\
\hline & Викоовсяная смесь & Озимая пшеница & Просо \\
\hline Вспашка оборотным плугом & $55,93 / 54,54$ & $27,4 / 32,6$ & $28,3 / 26,9$ \\
\hline Вспашка ПЛН-3-35 & $46,94 / 58,55$ & $35,2 / 34,8$ & $22,8 / 23,2$ \\
\hline Обработка КОСом & $54,46 / 32,35$ & $25,6 / 34,9$ & $25,3 / 27,5$ \\
\hline Обработка плоскорезом & $50,80 / 30,95$ & $28,9 / 34,3$ & $21,5 / 20,7$ \\
\hline Нулевая обработка & $31,34 / 30,8$ & $28,3 / 32,3$ & $17,2 / 15,1$ \\
\hline
\end{tabular}

* отечественная сеялка С3-5,4 / импортный посевной комплекс John Deere 730.

Из таблицы видно, что наиболее продуктивна викоовсяная смесь на 3/м при вспашке
ПЛН -3-35 при посеве (John Deere 730) и составляет 58,55 ц/га, а наименее дает нулевая 
обработка при посеве (John Deere 730) - 30,8 ц/га. Это можно объяснить тем, что при вспашке улучшаются агрофизические показатели почвы. При нулевой обработке почвы наблюдается обратная тенденция. При анализе продуктивности озимой пшеницы можно сделать вывод, что наибольшая урожайность наблюдается в варианте опыта со вспашкой ПЛН-3-35 при посеве озимой пшеницы С3-5,4 и составляет 35,2 ц/га, а наименьшая при обработке КОС-ом при посеве озимой пшеницы С3-5,4 - 25,6 ц/га. Если анализировать урожайность при посеве John Deere 730, то можно сказать следующее: урожайность по всем вариантам опыта практически не изменяется. При анализе продуктивности проса наибольшая урожайность наблюдается в варианте опыта со вспашкой оборотным плугом при посеве С3-5,4 - 28,3 ц/га, а при обработке почвы КОСом урожайность проса незначительно отличается от вспашки оборотным плугом и составляет 27,5 ц/га при посеве
(John Deere 730). В нашем опыте из всех вариантов обработки почвы под просо наиболее целесообразной с точки зрения засоренности и экономии ресурсов является обработка почвы комбинированным агрегатом КОС.

Видовой состав и особенно количество сорняков изменяются в зависимости от климатических условий, возделываемой культуры, агротехнологии и т.д.

Приемы современного земледелия направлены на поддержание численности сорняков на уровне, не оказывающем отрицательного влияния на урожайность сельскохозяйственных культур. Внутри каждого географического региона сорный ценоз складывается из определенных видов растений $[6$, 15]. Флористический спектр сорняков любого агроценоза включает повсеместно распространенные виды, которые отличаются высокой конкурентоспособностью (бодяк полевой, осот полевой, пырей ползучий, вьюнок полевой, щирица запрокинутая).

Таблица 3 - Средняя численность сорняков за 3 года исследований (2010-2012), шт/м²

\begin{tabular}{|c|c|c|c|c|c|c|c|c|c|c|}
\hline \multirow{3}{*}{ Видовой состав сорняков } & \multicolumn{10}{|c|}{ Численность сорняков, шт/м² } \\
\hline & \multicolumn{5}{|c|}{ при посеве C3-5,4 } & \multicolumn{5}{|c|}{ при посеве John Deere 730} \\
\hline & 1 & 2 & 3 & 4 & 5 & 1 & 2 & 3 & 4 & 5 \\
\hline Вьюнок полевой & 13,3 & 2,3 & 7 & 5 & 2,3 & 6,6 & 3,6 & 8,6 & 6,3 & 3,6 \\
\hline Хвощ полевой & 16 & 26,3 & 8,3 & 9,6 & 49,6 & 38,3 & 32,3 & 30,6 & 21,6 & 59,3 \\
\hline Редька & 7 & 8 & 8 & 11,3 & 2,6 & 17 & 8,3 & 8,3 & 7 & 0,6 \\
\hline Просо куриное & 3,3 & 2,6 & 7 & 6,3 & 10,6 & 1,3 & 1 & 4,3 & 7,3 & 16,6 \\
\hline Бодяк & 2 & 6,3 & 4,6 & 9 & 8 & 4 & 4 & 3 & 4 & 4,6 \\
\hline Сурепка обыкновенная & 3 & 2.3 & 3 & 0,3 & 1 & 1 & 0,3 & 2 & 4,3 & 6,6 \\
\hline Мышиный горошек & 2,6 & 4 & 1,3 & 4 & 4 & 1 & 4 & 2 & 3,6 & 2,6 \\
\hline Фиалка & - & 1,3 & 2 & 5 & 0,3 & - & 0,6 & 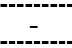 & 2,3 & - \\
\hline Щирица запрокинутая & 1,6 & 3,6 & 5 & 7,6 & 2,6 & 4 & 3,6 & 4,3 & 6,3 & 8 \\
\hline Мышей сизый & 7,3 & 9 & 12 & 11,3 & 91,6 & 7,3 & 5,6 & 2,6 & 10,3 & 73,3 \\
\hline Марь белая & - & 2,3 & 3,3 & 1,3 & - & 0,3 & 1 & 2,6 & 2,6 & 4 \\
\hline Пырей & 2,3 & 4,6 & 6 & 4,6 & 7 & 4,6 & 5 & 4,6 & 5,6 & 10,3 \\
\hline Горец шероховатый & - & - & - & 0,6 & - & 0,3 & - & - & - & - \\
\hline Пикульник & - & - & 0,3 & 0,3 & - & - & 0,3 & - & - & - \\
\hline Мокрица & - & 0,6 & 3,6 & 2,6 & - & 2,6 & 1,3 & 1,3 & - & - \\
\hline Подмаренник цепкий & 0,3 & - & 0,3 & - & - & - & - & 0,6 & - & - \\
\hline Ярутка полевая & - & - & - & - & - & - & - & 0,3 & - & - \\
\hline Всего & 59,7 & 73,2 & 71,7 & 84,1 & 179,6 & 88,3 & 71,3 & 75,1 & 80,2 & 189,5 \\
\hline В т.ч. многолетних & 33,6 & 39,5 & 25,9 & 33,5 & 66,9 & 53,5 & 44,9 & 46,8 & 36,5 & 77,8 \\
\hline
\end{tabular}

Численность и видовой состав сорняков зависит от засоренности почвы вегетативными зачатками и семенами сорняков. В звене севооборота викоовсяная смесь на з/м - озимая пшеница - просо изменялся видовой состав сорняков. При возделывании викоовсяной смеси на 3/м преобладали мышей сизый, хвощ полевой и вьюнок полевой. На озимой пшенице в начальных фазах роста отмечались в большей степени мышей сизый и хвощ полевой, а менее - редька дикая, бодяк полевой, пырей ползучий. В конце вегетации немного увеличивалось количество щирицы запрокинутой и пырея ползучего. В посевах проса в начале вегетации преобладали просо куриное и хвощ полевой, а в конце - просо куриное. Тип засоренности на опытном поле представлен в основном корневище малолетними сор- 
няками. Из таблицы видно, что наибольшая средняя численность сорняков за 3 года исследований наблюдается при нулевой обработке почвы как при посеве John Deere 730 -

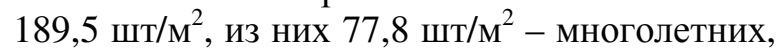
так при посеве С3-5,4 - 179,6, 66,9 шт/м² многолетних. Наименьшая засоренность при посеве С3-5,4 малолетними сорняками по варианту вспашки оборотным плугом - 59,7 шт $/ \mathrm{M}^{2}$, а многолетними при обработке почвы KOSoм - 25,9 шт/м². При посеве John Deere 730 наименьшая засоренность малолетними сорняками наблюдается при вспашке ПЛН -3$35-71,3$ шт/м ${ }^{2}$, а многолетними при обработке почвы плоскорезом - 36,5 шт/м². В целом по всем вариантам обработки почвы, кроме нулевой средняя численность сорняков, шт/м ${ }^{2}$ незначительно изменяется. Больше всего распространен мышей сизый и хвощ полевой. Большое количество хвоща объясняется слабокислой реакцией почвы (pH 5,5-4,9).

Смешанный тип засоренности отличается наибольшей вредоносностью, которая учиты- вается показателем экономического порога вредоносности. Так, для озимой пшеницы экономический порог вредоносности состав-

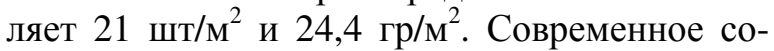
стояние агроэкосистем зависит от климата, географического расположения, культуры, агротехнологии, сорта, типа засоренности. Выбор количественных и визуальных методов учета засоренности посевов определяется задачами и направленностью проводимых исследований.

В современной ситуации важно продолжать мониторинговые исследования состояния агроэкосистем (состава и структуры сорного компонента, продуктивности возделываемой культуры). Это позволит характеризовать популяционную динамику сорных растений, их взаимоотношение с определенной культурой, влияние на засоренность той или иной современной агротехнологии и планировать меры по сдерживанию обилия сорняков на безопасном для культуры уровне.

\section{БИБЛИОГРАФИЯ}

Агроэкология / Под ред. Черникова В.А. М.: Колос, 2000. $536 \mathrm{c.}$

Баздырев Г.И. Сорные растения и меры борьбы с ними в современном земледелии. М.: Изд-во МСХА, 2004. 288 с.

Булохов А.Д. Экологическая оценка среды методами фитоиндикации. Брянск: Издво БГПУ, 1996. 104 с.

Власенко Н.Г., Солосич Н.И., Власенко А.Н., Кудашкин П.И. Фитоценологические методы оценки засоренности посевов сельскохозяйственных культур. Метод. Пособие. Новосибирск, 2000. 36 с.

Интегрированные системы защиты сельскохозяйственных культур от вредителей, болезней и сорняков. Рекомендации / Под ред. Сорока С.В. Минск: Бел. наука, 2005. $462 \mathrm{c.}$

Исаев В.В. Прогноз и картографирование сорняков. М.: Агропромиздат, 1990. 243 с.

Лунева Н.Н. К вопросу о засоренности посевов сельскохозяйственных культур на территории России в начале третьего тысячелетия // Фитосанитарное оздоровление экосистем. СПб.: ВИЗР, 2005. T.1. c. 332-334.
Мальцев А.И. Сорная растительность СССР и меры борьбы с нею. Л.: Сельхозгиз, 1936. $317 \mathrm{c}$.

Марков М.В., Куликова Н.М. Сорно-полевая растительность и методы ее изучения. Казань, 1964.246 с.

Методы мониторинга и прогноз развития вредных организмов / Под ред. Захаренко В.А., Гричанова И.Я. М.: РАСХНВИЗР, 2002. $96 \mathrm{c}$.

Протасова Л.Д., Ларина Г.Е. О методологии мониторинга сорной растительности агроценозов // АГРО ХХІ. 2002. №6. с. 2-3.

Смирнов Б.М. Методика и техника учета сорняков // Тр. НИИСХ Юго-Востока. Саратов, 1969. Вып. 26. 253 с.

Туликов А.М. Методы учета и картирования сорнополевой растительности. Уч.пособие. М.: МСX СССР, МСXА, $1974.47 \mathrm{c}$.

Хржановский В.Г. Ботаническая география с основами экологии растений. М.: Агропромиздат, 1986. с. 255.

Ульянова Т.Н. Сорные растения во флоре России и других странах СНГ. СПб.:ВИР, 1998. 344 с. 